\title{
Factory Templates for Digital Factories Framework ${ }^{\text {is }}$
}

\author{
Azevedo Américo*, Almeida António \\ INESC Porto-Institute for Systems and Computer Engineering of Porto, Faculdade de Engenharia da Universidade do Porto, Rua Dr. Roberto Frias, 378, 4200-465 Porto, Portugal
}

\section{A R T I C L E I N F O}

\section{Article history:}

Received 7 December 2010

Received in revised form

21 January 2011

Accepted 15 February 2011

Available online 21 March 2011

\section{Keywords:}

Factory Templates

Factory Life Cycle

Estimation

Management Knowledge

Digital Factory

Enterprise Reference Model

\begin{abstract}
A B S T R A C T
The global industry is currently facing a growing increase in the competitiveness that forces companies to adopt and develop new strategies and methods of production. Therefore, one of the most relevant challenges in manufacturing engineering is innovatively integrating Product, Process and Factory dimensions and life cycles, in a holistic approach, from design to recycling/disposal and reuse. The challenge faced here is the synchronization and simultaneous generation of all three-domain models by integrating manufacturing engineering knowledge into the early stage of the modelling and planning processes.

The next generation of factories has to be modular, scalable, flexible, open, agile and knowledgebased in order to be able to adapt, in real time, to the continuously changing market demands, technology options and regulations. Therefore, integration, flexibility and efficiency requirements and the ability to simulate the production life cycle of a factory play a crucial role in decreasing ramp-up and design times. Furthermore they play a crucial role in improving the performance in the evaluation and reconfiguration of new or existing facilities, in supporting management decisions and providing tools that can guarantee real-time performance monitoring.

Therefore, it is necessary to research and implement the underlying models and ideas during the foundation stage of a new conceptual framework, which is designed to be implemented in the next generation of factories. This will be supported by suitable Information and Communication Technologies (ICT) and digital infrastructures and should lay down the foundations for future applications in this research area-the industrial paradigm of "Factory as a Product".

In line with the context presented here, we propose the development of factory templates to address the design and operation practices throughout the entire life cycle of the factory.

Different dimensions of the factory templates are presented in this paper; they cover the design and creation of the factory, its remodelling and even the disassembly and recycling stages. This entire study takes into account relevant factors such as costs, quality, time, flexibility, environmental and social issues and energy efficiency. Throughout the article, different kinds of models are presented, which describe and adjust the structure of the analysis, design and development of a factory integration project that helps provide a formal analysis of the system. Furthermore, templates integrating the factory's response to internal and external disturbances will also be developed.
\end{abstract}

(c) 2011 Elsevier Ltd. All rights reserved.

\section{Introduction}

In this climate of slow economy growth within the economies of developed countries companies are facing an extreme level of competitiveness. Furthermore, a transfer of power from companies to customers has been observed, which has caused a continuous decrease in product life cycles, a higher replacement rate of products and services and a significant change in business and technological processes, plant facilities and in human and technical resources. Indeed, one of the most important characteristics of

\footnotetext{
The author gratefully acknowledges the CSU East Bay University for support of the project.

* Corresponding author. Tel.: +351 222094399; fax: +351222094350.

E-mail address: ala@fe.up.pt (A. Azevedo).
}

today's enterprises is that they are exposed to constant changes. Therefore, the development of a discipline that organises all knowledge needed to identify the need for change in enterprises and to carry out that change in an efficient and sustainable way is now necessary.

The above mentioned challenges have led to the development of an innovative strategy and a new industrial paradigm is now essential in order to guarantee competitiveness with a sustainable business vision. From a manufacturing perspective it is becoming progressively clearer that the next generation of factories needs to be modular, scalable, flexible, open, agile and knowledge-based in order to be able to adapt, in real time, to the continuously changing market demands, technology options and regulations. In addition, this new generation of factories should be able to integrate models and strategies capable of adapting their 
production system to the market's demands, of accelerating the plant design and of optimising production.

In order to achieve this, new methods of capacity planning must be developed and introduced, forecasting and analysis tools must be included in the processes of factory management and techniques to anticipate and improve reactions to internal and external disturbances must also be developed. Furthermore, in order to achieve the flexibility and efficiency requirements, the ability to simulate and study the production life cycle of a factory becomes crucial, not only in decreasing ramp up and planning times but also to improve performance in the evaluation and reconfiguration of new or existing facilities, supporting decisionmakers and providing tools that can guarantee real-time performance monitoring.

Therefore, it is necessary to research and implement the underlying models and ideas during the foundation stage of a new conceptual framework that is designed to be implemented in the Next Generation Factory (Factories of the Future) [6,19]. It is also meant to lay down the foundations for future applications in this research area. The framework that supports the next generation of factories should promote major time and cost savings, while improving performance in the design, management, evaluation and reconfiguration of new or existing facilities, supporting the ability to simulate and estimate a dynamic and complex behaviour over the entire life cycle of the Factory, based on the industrial paradigm "Factory as a Product" $[7,18]$.

The development of the Factory Templates component aims to be able to fulfil many of the requirements and functions previously mentioned. This approach aims to support process planning, integrating the industrial knowledge acquired with best practices and also evaluating their performance so as to improve them.

Different concepts of factory templates are presented in this paper, from the design and creation of the factory, to its remodelling or even disassembly and recycling stages. This entire study takes into account relevant factors, such as costs, quality, time, flexibility, environmental and social issues and energy efficiency. Throughout the article, we present different kinds of models that describe and adjust the structure of the analysis, design and development of factory integration issues and data processing topics. This helps to provide a formal analysis of the system.

Furthermore, templates incorporating the factory's response to internal and external disturbances will also be developed. They will focus on factory designs and operational strategies, efficiently addressing fluctuating market demands. The templates will also incorporate flexibility measurements as attributes for the factory designs. The developed templates will not only take into consideration the physical and operational forms of the factory itself, but they will also incorporate product and process layouts and strategies.

The Factory Template as a functional component has been developed within the framework of a large research project called Virtual Factory Framework. This project, which will be briefly presented in the following chapter, aims to support and provide all of the functionalities required for the next generation factories within the context of Factory of the Future initiative [28].

The paper is organised as follows: the next section presents an overview of the Virtual Factory Framework concept and its goals, as well as the Digital Factory paradigm. In this section, the concepts of "Factory as a Product", "Factory Life Cycle" and "Digital Factories" will be introduced. The third section addresses the most relevant Enterprise Reference Models that respect and fulfil the Generalised Enterprise Reference Architecture and Methodology (GERAM) perspectives and requirements. The concepts and foundations of WorkFlow, Data Fusion and Forecasting issues will also be presented. These two concepts will strongly support the Performance Value Estimator tool (PVE) presented in the following section. The forth section presents the factory template approach (architecture and concepts), as well as the static and dynamic domains that constitute this approach. Finally, discussions about experimental results and conclusions are presented in the fourth and fifth sections, respectively.

\section{Research context}

Since the main purpose of this research document, the concepts and approaches behind this study and the paper structure are known, it is important to clearly understand which are the European projects and initiatives that have supported and stimulated the Factory Template research. There are two principal European projects that, because of their importance in the definition of concepts and pillars behind the next generation of factories, should be used as a plumb line-the "Virtual Factory Framework" (VFF) [6] and the "Factory of the Future" (FoF) [28].

\subsection{Factory of the Future initiative}

The Factories of the Future (FoF) initiative aims at helping EU manufacturing enterprises, particularly SMEs, adapt to global competitive pressures by improving the manufacturing technological base across a broad range of sectors. In particular, the Information and Communication Technologies (ICT) contribution to this initiative aims to improve the efficiency, adaptability and sustainability of manufacturing systems, as well as improving their incorporation of business processes in an increasingly globalised industrial context.

The ability to produce large varieties of sophisticated products requires manufacturing infrastructures to be flexible, fast and reactive. Lean and easy-to-implement ICT enables those infrastructures to be resource efficient, safe and cost effective, as well as to improve management efficiency of networked and sustainable business operations. At the same time, it enables the participation of SMEs in virtual factory environments.

Typically, in organisations, the process data are vast and widely dispersed. Due to this, it becomes increasingly complicated to combine, manage and integrate a large variety and amount of available data. Therefore, it is crucial to develop and integrate tools for data fusion approaches in the company's working methods. Fusion is the integration of information from multiple sources to produce specific and comprehensive unified data about an entity. This methodology makes it possible to gather data in a useful way within a decision-support system. This represents an important advantage in the current business environment.

In line with the challenges proposed by the FoF initiatives [24,27], several specific projects on Digital Manufacturing are being developed, such as, "Modular Plant Architecture"MPA [30], "A configurable virtual reality system for Multi-purpose Industrial Manufacturing Applications"-IRMA [24], "Digital Factory for Human-Oriented Production System"-DiFac [29] and finally "Virtual Factory Framework"-VFF studied the idea of introducing new digital and virtual technologies into the manufacturing sector.

The expression "Digital Factory" means [21] a simulation of all activities during the entire life cycle of a factory. However, this innovative concept involves much more than just the use of simulation tools. It imposes new types of factory organisation and an intensive collaboration between the manufacturer and the subcontractors. The data outcome of every step of the workflow should be specified and the levels should be stored in a global factory-wide database. As a final target, it is expected that the development and production will only begin if the respective 
simulation shows that product and production will meet the given investments, the predefined time schedule and the necessary quality. Therefore, manufacturers have coined the concept "Digital Factory" to designate a network of digital models, methodologies and applications used to integrate the planning and design of manufacturing facilities with the manufacturing process itself, following the entire life cycle of the factory, as shown in Fig. 1.

Automotive companies such as Daimler, General Motors, Volkswagen and Toyota have made significant progress towards this vision. Using this paradigm, they have designed and constructed facilities with fewer delays and budget overruns, achieving a start off production that is faster than what was possible using previous methods [20].

With regards to the Digital Factory methodology, the Factory Planning is considered to be the central process because it is normally capable of joining all of the available as-built information, of determining the basic constraints of the entire factory before detailed planning is undertaken, of consolidating information during the final planning phase and finally, of providing

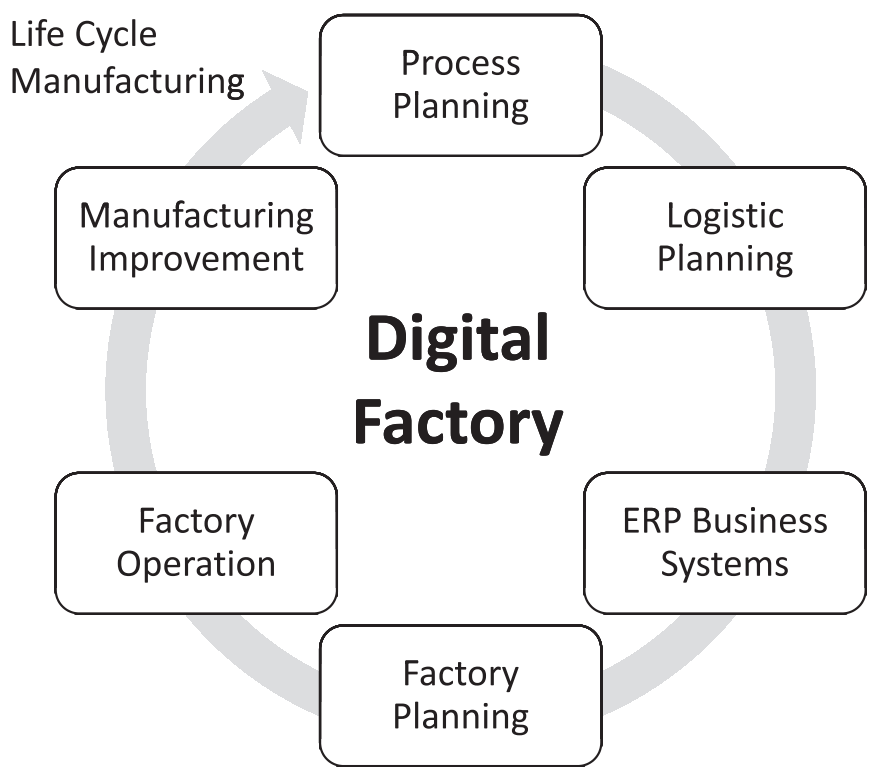

Fig. 1. Digital Factory Planning includes process, logistics, Business and Factory planning, Factory Operation and Manufacturing Improvement. important and detailed information for manufacturing operations. To create a detailed factory plan that can be used to construct and operate a manufacturing facility, all previously created information must be integrated and analysed. Therefore, following this approach, it is possible to achieve an optimal factory layout that supports the manufacturing process, optimises space, production and logistic requirements, connects to enterprise resource planning systems (ERP) and guarantees high maintainability and profitability.

Following this approach, the main focus of the digital factory concept is the process planning integration that includes product design, process planning and the planning of the manufacturing operation. Integration shortens the time and delay between these steps and gathers together the different planning groups. It offers dedicated tools and provides all of the project's team members with accurate and up-to-date information right at the beginning of the planning phase and throughout operations until the facility is renewed.

\subsection{Virtual factory framework}

The VFF research project title "holistic, extensible, scalable and standard Virtual Factory Framework" [6] proposes an innovative framework defined as "an integrated virtual environment reporting the design and management of the factory entities, ranging from the single product to the network of companies, during all the phases of the life cycle of the factory".

The primary objective of the VFF project is to research and develop tools that support the next generation of Virtual Factories. This interacts with the Real Factory in order to achieve time and cost savings, while increasing performance in the design, ramp-up, management, evaluation and evolution of new or existing facilities. To achieve these goals, techniques and methods that support the ability to simulate the different dynamic complex behaviours over the entire life cycle of a factory, must be developed. The life cycle of the factory starts with the site planning and the design of the facilities and infrastructure. This is followed by the construction phase, the installation of machinery and finally, the start of production when the factory goes into operation and is supported by maintenance and by the reconfiguration of products and processes.

Fig. 2 illustrates the close relationship between product, process and factories' decision-making along their life cycles. The challenge faced here is the synchronization and simultaneous generation of all three-domain models by incorporating, using/reusing manufacturing

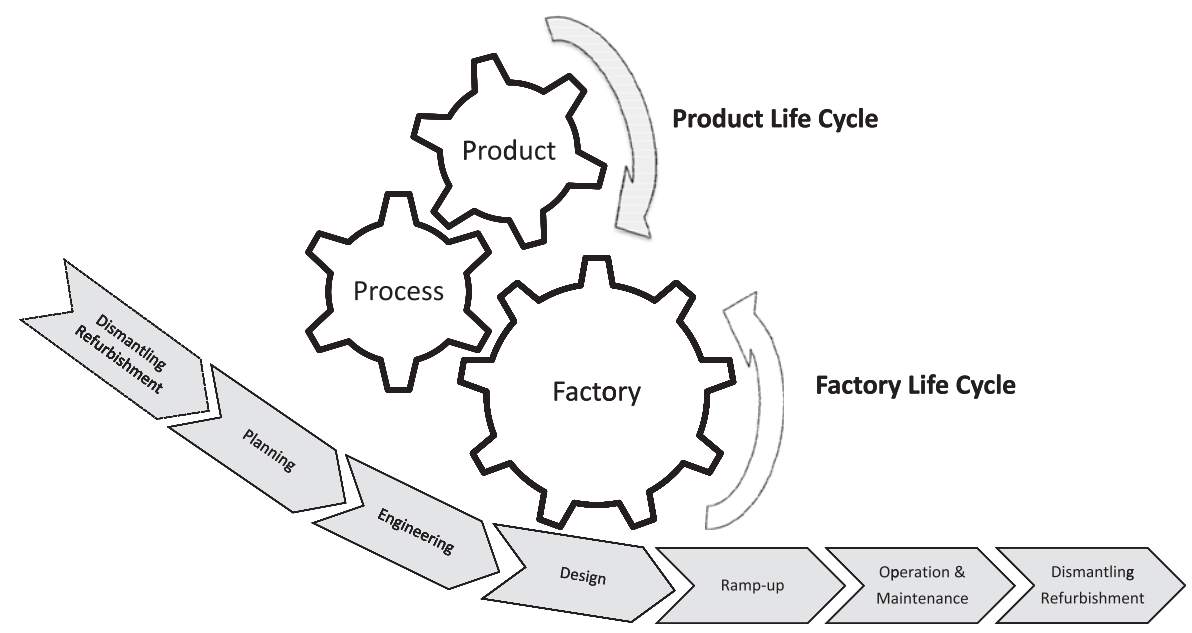

Fig. 2. Factory as a Product. 
engineering knowledge into the early stages of the modelling and planning processes [7].

Factories operate as large networks of information and are part of logistics networks that support supply-chains from customer's orders, for consumable materials and waste, for factory machines, equipment and tools. Therefore, a factory as a whole is made up of basic components that support factory transformability or changeability. This vision can benefit from applying the life cycle paradigm to the factory as a product. It is therefore possible to view the factory as a big and complex product and take some new and innovative notions, for example:

- Being digital in a static state and virtual in a dynamic state. Digital manufacturing uses a wide range of engineering and planning tools and applications to incorporate new efficient and effective information and communication technologies into manufacturing processes;

- Having a long life (managed by the Knowledge repository);

- Being subject to permanent adaptation and transformability;

- Transferring the life cycle paradigm, optimisation and value creation from products, process and technology for the factory.

Considerable benefits can be achieved if these entities are taken into consideration, such as faster time-to-market, lower costs, reduction of rework and rejection dates and increased component and technology reuse.

The Virtual Factory Framework is based on four pillars $[6,18]$ : the reference model for factory planning, the Virtual Factory manager (VF Manager), the Virtual Factory Modules (VF Modules) and Knowledge. The first one is based on two key concepts; the "factory as a product" and the "non-linear, non-deterministic planning methodology". The referenced model establishes a coherent, standard, extensible data-model as the basis for the common Factory Object. The VF Manager handles the common space of abstract objects, representing the factory. The VF modules are the decoupled functional modules that implement the various tools that work for the Factory design, evaluation, evolution, management, etc. Lastly, the Knowledge pillar is seen as the engine of the VFF concept, it represents a wider range of complex systems and promotes a greater comprehension of the methods adapted at the factory. This is the component that will be explored and developed in this paper.

From a VFF perspective, the development of a framework and a reference model for a holistic view of the factory will allow for a wider perspective when compared to the methods and techniques currently in use. It will be capable of describing the factory as a whole, as far as processes, dependencies and interrelations, factory modules and data flows are concerned. Plenty of tools and software have been developed with the aim of optimising production processes, factory planning and design. However, there are still many issues that need to be addressed, such as the methods and tools used to create a configurable plant, to enhance process management and to manage the efforts of moving towards Mass customization Products.

In summary the VFF approach offers important advances when compared to the state-of-the-art, for example:

- The development of a holistic view for the factory, considering both its physical dimensions and its evolution over time (factory life cycle);

- A definition of a reference framework for the factory planning activities;

- The development of a collaborative and extensible data model for product, process, resources and infrastructures to face the poor interoperability among different software platforms using a proprietary format;
- The development of new planning methods and tools, in particular for the configuration and reorganisation of production plants;

- Synchronization between the virtual and real factory.

\section{State-of-the-art}

In the domain of manufacturing research it is possible to conclude that there are no direct contributions addressing the "Factory Template" concept and addressing the supporting tools and models, which can be instantiated during the planning phases of factories. However, this theme is largely developed by the informatics and computer sciences that explore various aspects of this matter. Templates are so fundamental that any programmer has probably used them dozens of times without even thinking about it. One example of this is the development of business pattern templates which are used to formalize the idea of defining an algorithm in a class, yet leaving some of the details to be implemented in a subclass.

In line with this approach enterprise reference models will be discussed during the state-of-the-art chapter as a background to the Factory Template concept present in the following chapters. In addition, data handling tools such as Workflow modelling, data fusion and forecasting and estimation will be introduced to support process, product and factory information management and integration.

\subsection{Enterprise reference models}

There are elements and concepts that are common to all companies and factories, which support and show the relation between all aspects of the life cycle of the factory. These concepts support the development of an architecture, framework and methodology, which is necessary to plan and execute all engineering tasks for company integration that are fundamental for successful production and operation [18].

The application of system engineering concepts in the life cycle of the factory makes it possible to create graphical models that illustrate the main tasks and concepts. This sketch, which can be called "architecture", can be structured and organised in the form of templates. There are three types of frameworks:

- Specific implementation for a specific industry and phase.

- Generalised enterprise reference architecture and methodology (GERAM) [9,25]. These are models or frameworks of reference for all life cycles of factories. They can be implemented and used in all types of industries and phases. Furthermore, they can be seen as excellent guiding tools. The aim of GERAM is to define a complete collection of tools, methods and models that can be employed by an engineering enterprise in an integration effort.

- Partial models that can be applied to a few industries or factories.

Therefore, GERAM provides a description of all of the elements recommended for enterprise engineering and integration. Therefore it sets the standard for the collection of tools and methods from which any enterprise would benefit from in order to more successfully tackle initial integration design and the change processes, which may occur during the enterprise operation lifetime. In order to structure the factory templates, it is necessary to analyse different models and architectures that can be classified as GERAM models. Only this type of models will make it possible to develop and explore templates that can be reused and adjusted to all factories and types of industries in order to promote a better process and method systematisation, as previously explained. 
During the development of GERAM in 1996 by the IFIC/IFAC Task Force, the expectation was to develop an innovative methodology and enterprise architecture of reference. However, after gaining a better understanding of the already existing reference models, such as PERA, CIMOSA and GIM, it became clear that GERAM should not create a brand new reference model, but it should develop a new concept that would be able to incorporate all of the referred methodologies. This new approach was very important as each of these reference architectures has something unique to offer and none of them subsumes the other.

In line with this, during this section a series of architectures and methodologies that had supported GERAM, such as PERA and CIMOSA, will be presented. Zachman will also be presented as it also aims to respect the requirements imposed by GERAM, such as the GERA life cycle.

CIMOSA: Also known as Open System Architecture for CIM [8]. CIMOSA's primary objective is to develop an open architecture of reference for the implementation, definition and specification of CIM systems (Manufacture integration by computer). Furthermore, the framework offers an event-driven, process-based modelling approach that aims to incorporate essential enterprise aspects into one integrated model. The structure of the CIMOSA architecture is known as "CIMOSA CUBE", defining four different modelling perspectives: function, information, resource and organisation.

This method, which is intended to be applied throughout the pre-defined Factory LifeCycle, gives its own perspective on the architecture of reference, specifying procedures and guide operators, system managers and users.

PERA: The Purdue Enterprise Reference Architecture [5] aims to create a model of all company life cycles, targeting the manufacturing environment and simply applying that model to other enterprises. This architecture satisfies all currently known requirements of GERAM [9].

The generic model PERA includes three basic components:

- Human-Resources as Organisational Architecture;

- Manufacturing Equipment Architecture;

- Information System Architecture.
These components are described as the three columns that start with the creation and definition of a company and end with the dissolution of the company. Each one of these columns interfaces with the others and thus it is possible for them to relate to each other.

The PERA architecture states that the next level in structuring the company's model should have different "phases". Therefore, PERA breaks the life cycle into phases, as shown in Fig. 3. During each phase of the life cycle of the company different diagrams are used to reflect the development details at that moment and to monitor the way the enterprise goes from the initial definition step to dissolution, passing through the operation level. At each step or phase of the PERA model it is possible to define and discriminate documents and tools explaining the precedence between them and their usefulness.

It is essential that the interfaces between the different groups that develop the enterprise are always well coordinated and communicate with each other. For example, during the preliminary engineering phase, when the industrial processes are being defined, it is necessary for the information and control system, as well as the human and organisational system, to also be developed in parallel.

The Purdue Enterprise Reference Architecture includes as its main advantages: the possibility of providing a full life cycle for the facilities that are being developed within the company's project. It also offers a means to handle human and organisational factors inherent to these projects and to the company's approach to these projects, it offers a "phase" approach to reduce repeated work while carrying out projects, it offers an understanding of the dynamic interfaces between the different disciplines of engineering and management working on a particular project. It also presents informal models and templates of each phase in order to improve understanding and to monitor the work in progress and lastly and perhaps the best of all of the advantages is the fact that PERA diagrams look intuitively correct and present the life history in a way that follows the design that most engineers and managers in the industries have for their own plants and companies.

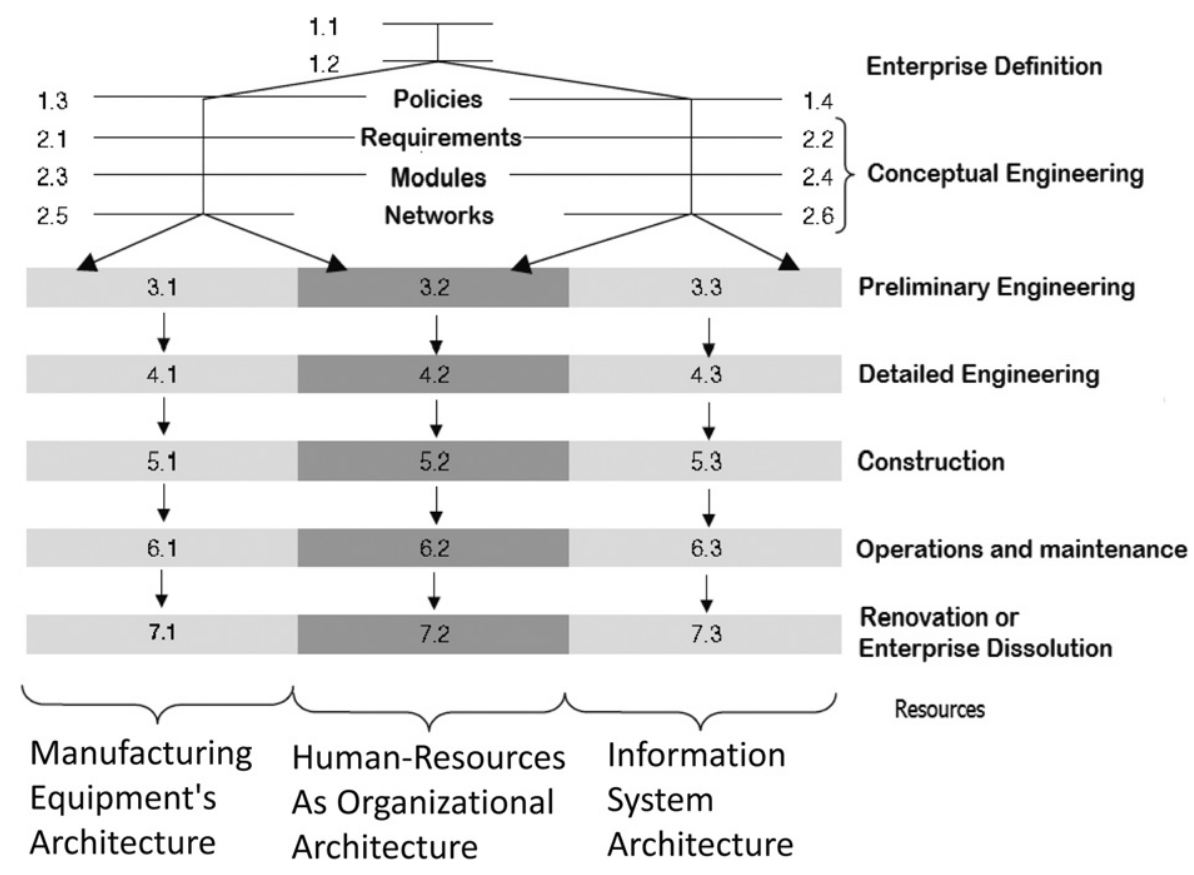

Fig. 3. PERA Architecture. 
ZACHMAN: The Zachman framework [3] was created in 1987 and instead of dividing the whole process into a series of processes, it organises it from the point of view of the various players in the process. This framework uses an original approach to the life cycle, presenting the life cycle phases as perspectives of the various stakeholders involved in the enterprise engineering effort. However, the different levels of abstraction used by the various stakeholders to consider the enterprise entity in question, match the GERAM life cycle. GERAM contains types of activities, while Zachman describes deliverables that certain stakeholders produce.

The previously described players include people who do business in a particular industry, business people who run the organisation, the system analyst who wants to represent the business in a particular industry, the designer who applies specific technologies to solve the problems of the business, the builder of the system and finally the system itself. Each of these actors is represented in the Zachman matrix as a row. On the other hand, the columns represent the things that are examined, specifically the data manipulated by an organisation (What), its functions and process (How), the location (Where), the events that trigger business activities (When), the people and organisations involved (Who) and the motivations and constraints that determine how the businesses behave (Why).

\subsection{WorkFlow management systems}

The WorkFlow process is a special kind of business process [22]. In fact, nowadays, this interesting approach can be used and applied in a wide range of activities. Therefore, the WorkFlow can be seen not only as an administrative business process, i.e. as a business process that delivers services or informational products but also can be seen to refer to the control dimension of a business process, i.e. the dependences of tasks that must be respected during the execution of a business process. A final and empirical interpretation is to consider those business processes as WorkFlow that can be supported by WorkFlow Management Systems (WFMS).

The main purpose of a WFMS is to support the definition, execution, registration and control of business processes. Thus, the WFMS is intended to take care of the task of delivering the right piece of work to the right resource at the right time while determining how the business process execution should continue. This can only be managed automatically by the WFMS using the model of the business process, also called WorkFlow definition. All tasks within the business process are distinguished here as well as their dependencies, incorporating the information on the type of resources that are required for the execution of each task.

The success of a WorkFlow system stands or falls on the quality of the workflow put into it. Petri Nets can be used as a tool to represent a process in a straightforward way and also to analyse these processes [23].

The classical Petri net [1] is a directed bipartite graph with two node types called places and transitions. The nodes are connected via directed arcs. Connections between two nodes of the same type are not allowed. Places are represented by circles and transitions by rectangles. At any one time a place can contain zero or a non-limited number of tokens, which are drawn as black dots.

The number of tokens may change during the execution of the net. Transitions are the active components in a Petri net can change the net's state according to the following firing rule:

- A transition $t$ is said to be enabled only if each input place $p$ of $t$ contains at least one token.
- An enabled transition may fire. If transition $t$ fires then $t$ consumes one token from each input place $p$ of $t$ and produces one token in each output place $p$ of $t$.

The classical Petri net makes it possible to model states, events, conditions, synchronizations, parallelisms, choices and iterations. However, the classical Petri net does not model data and time. To solve these problems many extensions have been proposed. Three well-known extensions of the basic Petri net model are the extension with colour to model data, the extension with time and the extension with hierarchy, to structure large models. A Petri net extended with colour, time and hierarchy is called a high-level Petri net. This tool can be seen as an important vehicle for modelling and implementing any kind of workflow since it adds value to the development process, this is advantageous if the workflow system has to be managed.

Clearly business logic can and should be represented using a graphical language. In the process dimension there are the tasks that need to be executed and their order is specified. In fact, there are some tools that play important roles in modelling and characterizing processes, such as swimlanes and matrix models. However, modelling a workflow process using Petri net not only becomes quite direct (tasks are represented as transitions, conditions are modelled by places and cases are modelled by tokens) but also presents plenty of other advantages [2]. As a graphical and mathematical tool Petri nets provide an excellent method for modelling, formal analysis and design of discrete event systems, fault detection and monitoring systems. In fact, simple analysis tools, such as reachability trees and the matrix equation can be very useful to guarantee a successful system response and performance.

In a simplified way a task can be associated with a piece of work, whose execution contributes to the completion of a business process. Task instances are executed by resources, such as a human or an application. The capabilities of a resource are given by a set of roles. Each task requires a specific role that is used to map task instances for resources. A workflow procedure defines a partial ordering of tasks to handle specific cases. The definition of a workflow process comprises a workflow procedure, a set of resources and a strategy to map task instances for resources.

In order to demonstrate the application of Petri nets as a workflow tool, Fig. 4 presents an example of a simple operational process model underlining its activities, resources, events and other workflow information.

A Petri net that models a workflow process definition (i.e. the lifecycle of one isolated case) is called a WorkFlow net (WF-net) [1] With this it is possible to draw a representation of the workflow, which is close to the business process we are working on. Another asset that this tool presents is that it offers many analysis techniques. In fact, this representation can be used as a starting point for various kinds of analysis. Therefore, it is possible to say that the Petri net representation can be used as an interface between the business process and the analysis method(s). In order to support the Petri-nets analysis there are some techniques that can be used to prove various types of properties, such as safety and invariance properties, deadlock, liveness, etc. This tool allows us to calculate performance measures, such as response times, waiting times, occupation rates, etc. This means that it is possible to evaluate alternative workflows.

\subsection{Data processing}

It becomes increasingly complicated to combine, manage and integrate a great variety and amount of dispersed available data. This means that it is crucial to develop and integrate tools for data fusion approaches into company working methods. As a general definition 


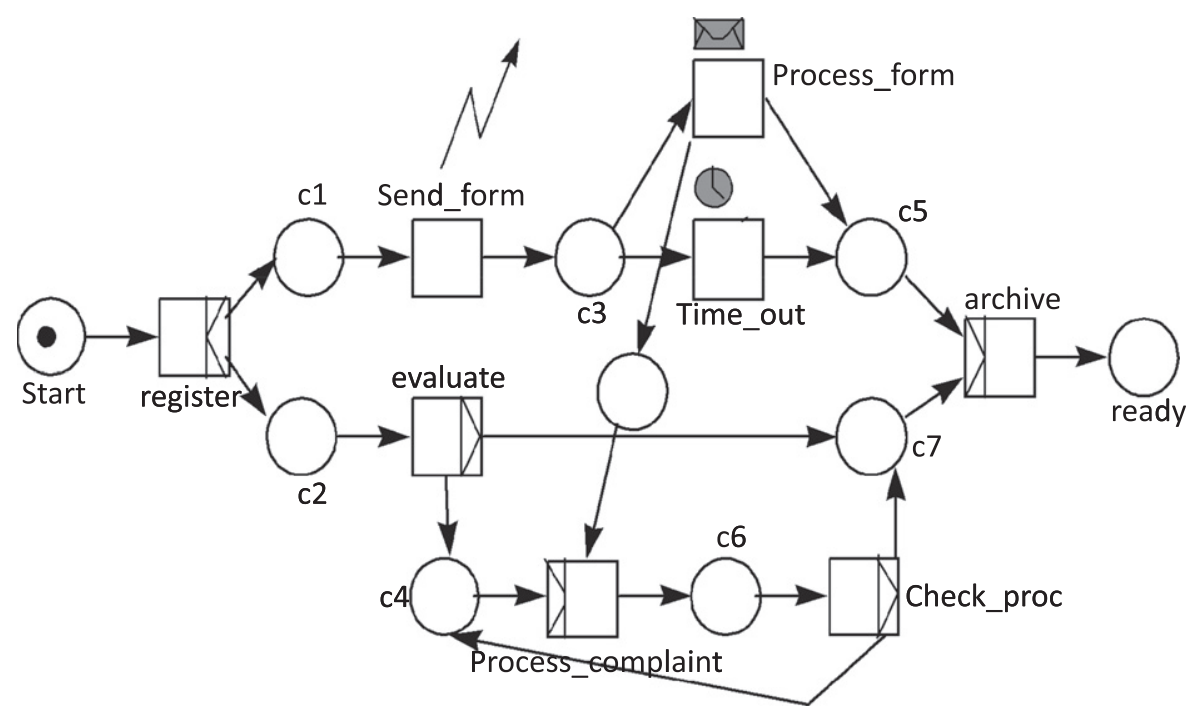

Fig. 4. Petri net application in Workflow modelling.

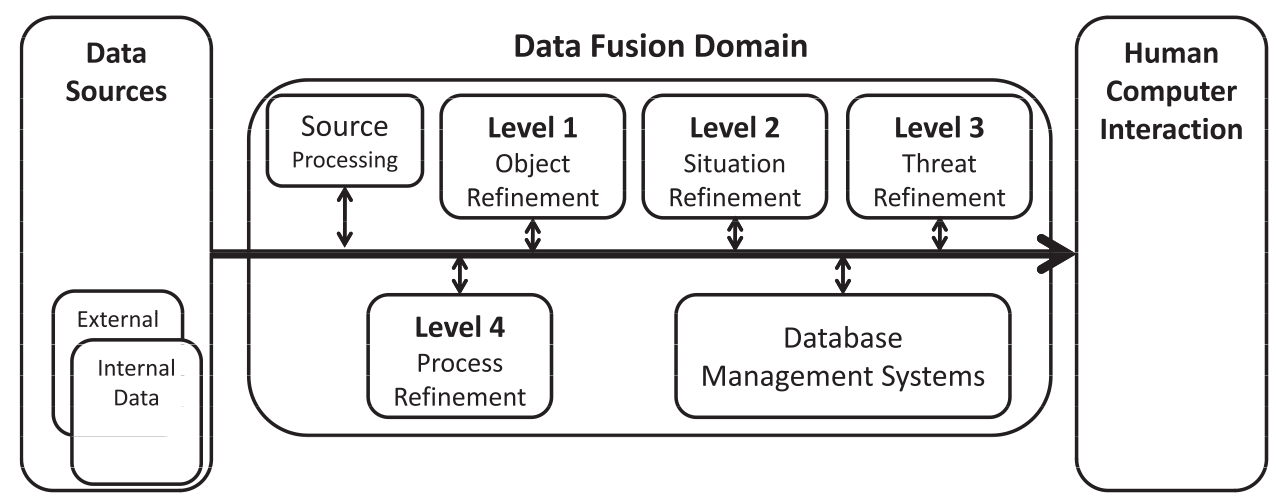

Fig. 5. JDL Functional Model.

we can consider fusion as the integration of information from multiple sources to produce specific and comprehensive unified data about an entity [13].

According to Hall and Llinas [13], Data Fusion is a "group of techniques that combine data from multiple sensors and related information from associated databases to achieve improved accuracies and more specific inferences than could be achieved using a single sensor alone". The term sensor, in a management subject, can be represented by a specific source with some intelligence, for instance the performance databases.

In fact, the processes of data fusion encourage the use of modern techniques such as the Kalman Filter, clustering algorithms, neural networks or decision-based methods like the Bayesian method, in order to identify targets or patterns [13] Furthermore, this methodology makes it possible to gather data in a useful way within a support decision system and this represents an important advantage for the current business environment.

One of the most influencing data fusion models is the JDL functional model, developed in 1988 [12]. The JDL process model is a functionally oriented data fusion model and it is intended to be general and useful across diverse areas and applications. This is a very useful tool for the visualisation of data fusion processes and also to facilitate its discussion and comprehension.

The JDL is divided into five main levels:

- Source Pre-processing (level 0) involves processing of individual sensor data to extract information, improve signal-to-noise ratio and preparation of data, such as spatiotemporal alignment for subsequent fusion processing;

- Object Refinement (level 1) combines all of the raw data to obtain the most reliable and accurate estimates of an entity's attributes and identity;

- Situation Refinement (level 2) develops a description of current relationships among entities and events in the context of their environment;

- Impact Assessment (level 3) projects the current situation into the future in order to increase processes and look for opportunities;

- Process Refinement (level 4) monitors the overall data fusion process to assess and improve the real-time system performance.

The JDL data fusion model also refers to sources such as human input, databases, local or external sensors with access to the data fusion system. This can be seen on the left side of Fig. 5. On the opposite side it is possible to see the Human Computer Interface block, which allows operators to interact with the system. Finally, the Data Management System provides management of data for fusion, such as measured data, environmental information, market data, models and estimators, among other factors.

In fact, data fusion is a technology that is growing; and it can be developed and applied to military matters, robotics and automation areas, medical diagnostics and smart buildings. However, it is also frequently used for environmental monitoring and to represent industry behaviour and performance [13]. In this 


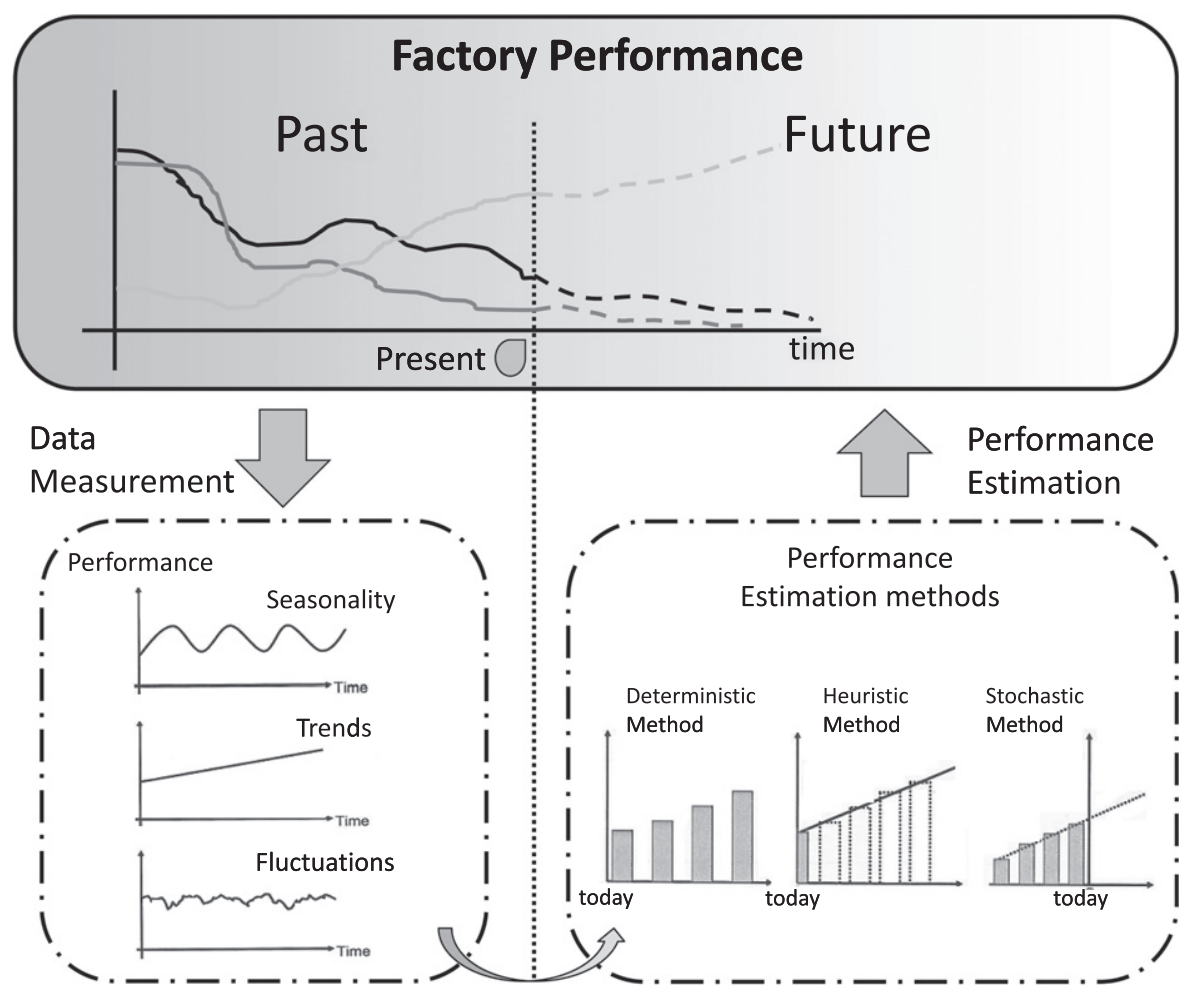

Fig. 6. Conceptualization for Factory Performance analysis and estimation.

context, the Performance Value Estimator tool, which will be explored in the next chapter, aims to apply these principles and methods in order to extract performance values and also to define targets, guaranteeing data reliability and accuracy.

Therefore, the intention with this document is to prove that a data fusion approach can be a crucial tool, not only to integrate business information but also to predict future performances and support decision makers.

\subsection{Data prediction}

Data fusion is an important stage of the data handling. In fact, there are factors such as, fluctuation caused by a sensor or by human error that can affect the successful extraction of important, meaningful and accurate information. However, after achieving a better understanding of the data and its meaning, it becomes clear that it is crucial to study its origin, calculate or detect possible seasonality and trends and try to predict its future behaviour (Fig. 6). In line with this approach there are a series of available forecasting and estimation tools that can provide the referred anticipation. Undeniably, there are some differences between estimation and forecasting. Estimation attempts to predict past, present and future values, while forecasting tools are only used to predict the future.

Historically, forecasting techniques have been of great scientific and industrial interests. With a preliminary study about estimation and prediction issues, it is possible to determine three main completely different forecasting methods. These can be seen in Fig. 6 [14].

The deterministic methods are supported by credible sources that are aware of future values beforehand. Indeed, this type of method is very interesting for quantitative planning. On the other hand, stochastic and heuristic methods are characterised as being based on past data. Despite being of simple application and having low computational costs, heuristic methods require sound knowledge of the system under study and are usually associated with large uncertainties. Stochastic methods, on the other hand, use mathematical methods based on regression analysis, moving averages or exponential smoothing, enabling the mathematical extrapolation of known data. If correctly applied, this type of method can generate predictions with low levels of error despite the need for a greater effort in its implementation.

Now that the methods normally used in forecasting issues have been presented, it is now important to understand that when estimation tools are applied in normal business environments, performance can be affected by three major factor types: seasonality, trends and statistical irregular fluctuations (Fig. 6). The seasonality and trends translate the long-term system behaviour and can be captured mathematically, while the data consists of fluctuations that affect the forecasting and estimation tasks. This makes them more difficult and less reliable on the short-term.

After the background of the static and dynamic approaches of the Factory Templates have been explored, it is now important to define its concepts and architecture, addressing its functionalities and the way they should fit together. Furthermore, during the following section how Factory Templates should be applied within a company will be explained and how its application can improve the company performance. This will be improved not only during a specific moment or life cycle stage but also throughout the whole life cycle of the factory, following the different products specifications that should be produced within a certain factory.

\section{Factory Template}

\subsection{Concepts and architecture}

Factories should be seen as enormous and complex products that require exhaustive planning processes during the whole life cycle, from its idealisation to its dismantling. Current 
research $[4,7]$ addresses these issues by developing new design methods for the Factory of the Future and by integrating new technologies and tools, which may be used to manage factories, products, processes and technologies over their life cycle, from engineering right up to decommissioning.

The factory planning process includes several concepts and elements present in almost all phases of the factory life cycle. These concepts highlight the development of methodologies necessary to plan and execute all engineering tasks associated with successful production and operations. Thus, the Factory Template [18] can be seen as a meta-reference model that embodies the company strategy (Fig. 7).

Factory Templates can be compared with software patterns, comparing their advantages and their final purposes. From software engineering, software patterns are patterns designed to provide reusable solutions to a commonly occurring problem. Therefore, as in software science, where the use of templates makes it possible to reduce the development time and to increase programming agility, in the manufacturing management science it is crucial to use models and standards that allow for the development of faster and more efficient systems. These systems present characteristics such as modularity and standardisation of industrial processes. Therefore, it is crucial to explore the advantages resulting from the similarity between the Factory Life Cycle Model and Pattern Life Cycle Model [18].

In order to enhance the perception of the factory as a product, Factory Templates have been developed in the VFF project. In fact, these templates must: support the design, operation and evaluation of factory phases, show how processes operate, compile perspectives of all of the stakeholders involved, structure the information that must be shared and show how it should be meaningfully analysed and reported.

Before new products start being produced effectively within a certain factory facility, exhaustive work must take place in order to guarantee an excellent manufacturing performance. Therefore taking into account that the product life cycle is getting shorter and shorter, companies should spend a significant amount of time and resources planning new processes and life cycles of factories. In order to make these processes faster and to lower expenditure on resources, Factory Templates aim to represent patterns that can easily be incorporated into new digital factory cases. Consequently, the main inputs required by the Factory Templates are the company strategy, product requirements, as well as rules and the Knowledge acquired through the entire lifetime of the factory.

Therefore, it is important to underline the importance of the Knowledge Management for the future generation of manufacturing. Multi-scale simulations are required with the ability to adapt to real or to forecast system behaviours, as described in Refs. [24,27]. Accordingly, new basic models of data processing and simulation techniques must be developed and extended by automated planning.

In line with the factory as a product paradigm, factories can be viewed as complex and long-life products operating through complex relationships between the material value chain and information chains, with both technical and human elements. In contrast to other complex products, factories require an overall system architecture that allows for continuous adaptation to the needs of customised products, economic environment and objectives. Consequently, in manufacturing, as in all complex systems, knowledge represents the key to maximising manufacturing success and the dynamics of this socio-technical system. This knowledge, which currently only exists implicitly within the skills of workers, technicians and engineers, is explicitly implemented in the systems of management, engineering and in the control of processes. Thus, it is essential to capture and store this knowledge within intelligence management systems, as well as to stimulate its flow between knowledge sources and all who seek knowledge in order to improve their work and optimise their processes.

The knowledge-based manufacturing strives to achieve a seamless integration of scientific, technical and organisational knowledge from all fields of production. Learning is a central feature in knowledge-based manufacturing: learning from experiments, learning from analysis of best practices, learning with

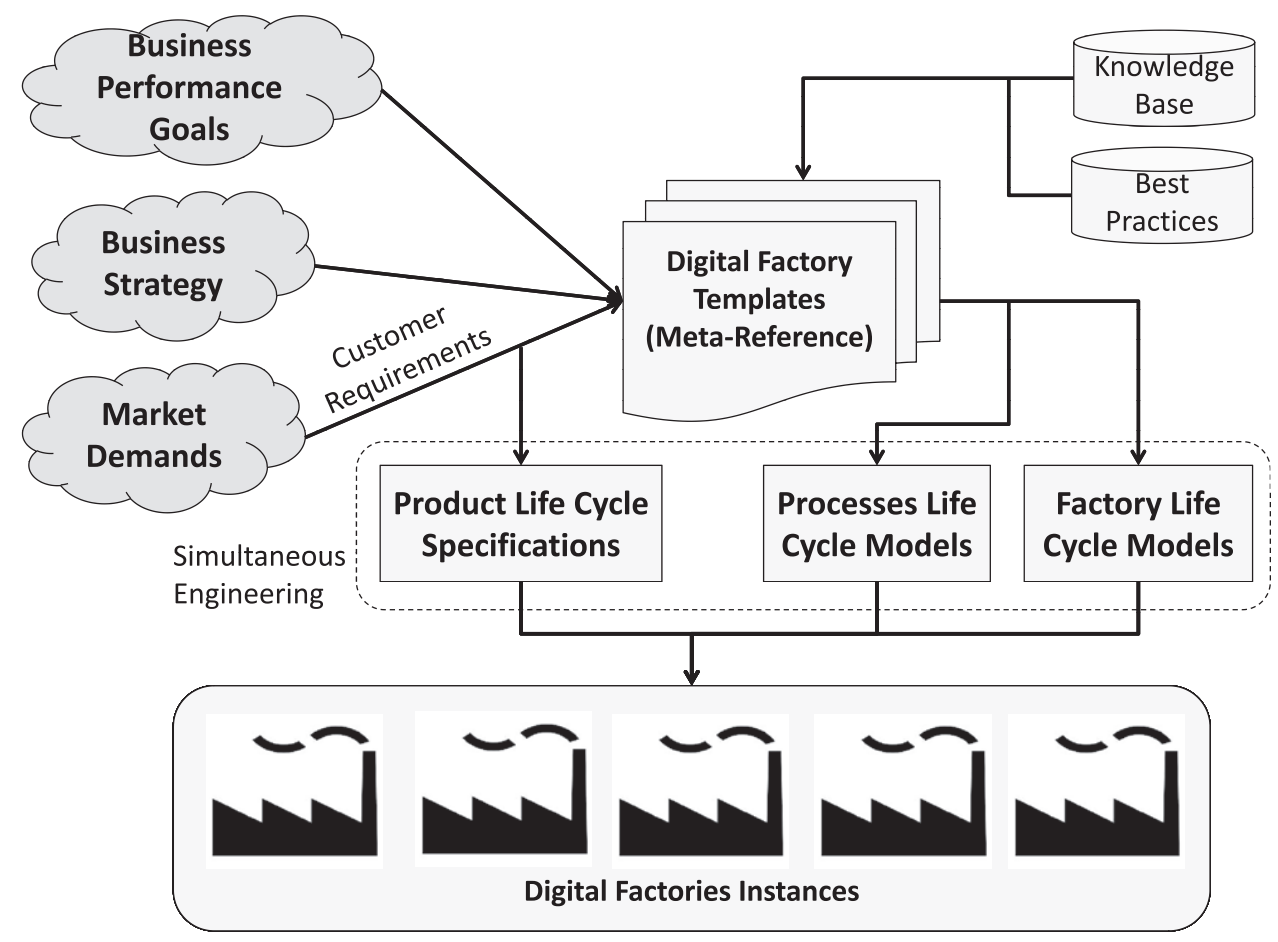

Fig. 7. Factory Template integration within Digital Factories. 
scientific-based methodologies or learning with simulation machines (learning from the future).Therefore, only by merging concepts such as Knowledge, products and the life cycles of factories, processes definition and workflow, it is possible to achieve efficiency and effectiveness during the operation stage. It can be observed in Fig. 7 that during the product process and the life cycles of the factory specification, Simultaneous Engineering [26] must be used in order to guarantee coherence and successful integration between them.

Finally, not only can different factory plans be performed, applying the company concept, but different instances of the same factory can also be achieved in order to compare and determine, through simulation, which instance will provide a better performance.

Subsequently, in order to achieve this purpose, Factory Templates will be divided into two main modelling components: Static and Dynamic strands. In the first component, factory templates should structure and manage documents, best practices, methods, techniques, processes and knowledge, as well as constraints, goals, requirements and concurrent engineering processes. The dynamic strand will incorporate forecasting exercises, internal and external disturbances analysis and performance evaluation of the real factory in comparison with the virtual factory instances.

In fact, all of this should be performed taking into account different factors and issues, such as production facilities, human roles, information and control systems, energy efficiency, environmental and social issues, among others.

In order to design and implement knowledge-based systems, great attention must be paid to the development of 'self-learning' systems. These should be able to use experience and histories of development processes when processing real-time data, in order to extrapolate information, predict future behaviours and to generate new knowledge by proposing several optional and solution alternatives. Knowledge-based systems, such as Factory Templates, will facilitate the rapid transfer of data across product-process domains and life cycle phases.

In conclusion, with the Factory Templates concepts for factories are expected to be developed. These concepts will be capable of adapting themselves continuously to changing market requirements or changing product and production technologies. This continuous adaptation at all levels of the factory requires explicit and implicit knowledge, hierarchical system architectures and takes into account the complexity and synergetic work of networks.

\subsection{Static modelling dimension}

Due to the market demands and current economic situation already described in the chapters below, knowledge management as well as factory image data fusion are becoming fundamental to ensure that an enterprise runs at peak performance and profitability. Furthermore in order for this management to reach this level, it needs an underlying data collection and management system that looks at the whole enterprise, as previously explained. Indeed, data acquired from the factory operation has very little value to process management if analysed in a standalone mode. This data must be analysed, converted into comprehensible information and delivered to the right person in order to take the right decision at the right time. However, to be effective, manufacturing management requires a well-designed set of data systems within the companies. These systems follow best practices and are compatible with one another from the level of the individual variable definitions, being able to use consistent data transfer and reporting language [10].
The Factory Templates' approach must define such a manufacturing data system, taking into account at each dimensional level the following issues:

- Industry best practices;

- How processes operate;

- Which data are required to monitor each process and how this data should be analysed;

- What reporting is required by those operating that process and those managing it;

- What information must be shared between different functional departments within the company and how it is meaningfully analysed and reported:

- How data from different sources are aggregated to produce Key Performance Indicators (KPIs), which integrate the manufacturing and business management concerns of the company.

In line with the requirements previously described, Factory Templates were divided into two main dimensions: Static and Dynamic domains. In this sub-chapter all of the state independent characteristics that should be taken into account when a company needs to plan, reorganise and design the new or existing manufacturing/business processes, facilities or resources will be analysed. In order to provide an answer to the topics proposed previously and with the different tools and methods that were outlined in this paper, it is important now to understand how all this information can fit together in order to create a framework capable of supporting the decision makers and also of helping the creation process and its sharing.

As shown in Fig. 8, we propose one framework divided into three levels: in the first level of abstraction we use a model similar to the PERA architecture in order to provide a more careful analysis and to give a well defined perspective on the strategy and best practices adopted by the company for the short or long term. At this level, important elements, such as human resources, environmental issues, the development of information and control systems, that will support the business model of the company and increase its dynamics and flexibility will be taken into consideration. The production facilities where factors, such as energy efficiency and costs, which play a crucial role, will also be considered It is necessary to follow the evolution of the factory, therefore the main Life Cycle phases should be taken into account: investment planning, engineering, process planning, construction and ramp-up, production, service and maintenance and finally, dismantling or refurbishment. As explained in Ref. [11], all of these and other main phases can be distributed through different strategic clusters: Strategic Planning, Structure Planning, Process Planning and Factory Operation.

In conclusion, we can say that at this level, the entire life cycle of the factory, from its definition to its renovation or dissolution, will be represented. At each stage, it should be explained which documents and typical deliverables should be taken into consideration and the different metrics and KPIs that will support our decisions and performance analysis. Therefore, the performance "AS-IS versus TO-BE" presents an interesting approach to the analysis if the drawn processes are being well executed and answering to the proposed requirements. "AS-IS" presents the reality, in other words, it represents the way that the process is being executed and the resulting performance. On the other hand, the "TO-BE" parameter handles the ideal/planed situation. Thus, once these two attributes are known, it is possible to evaluate both processes and the factory performance.

Subsequently, at this level, it is possible to have a global view of the implemented strategy and its structure. From this global view, we propose that all of the information is divided into two 


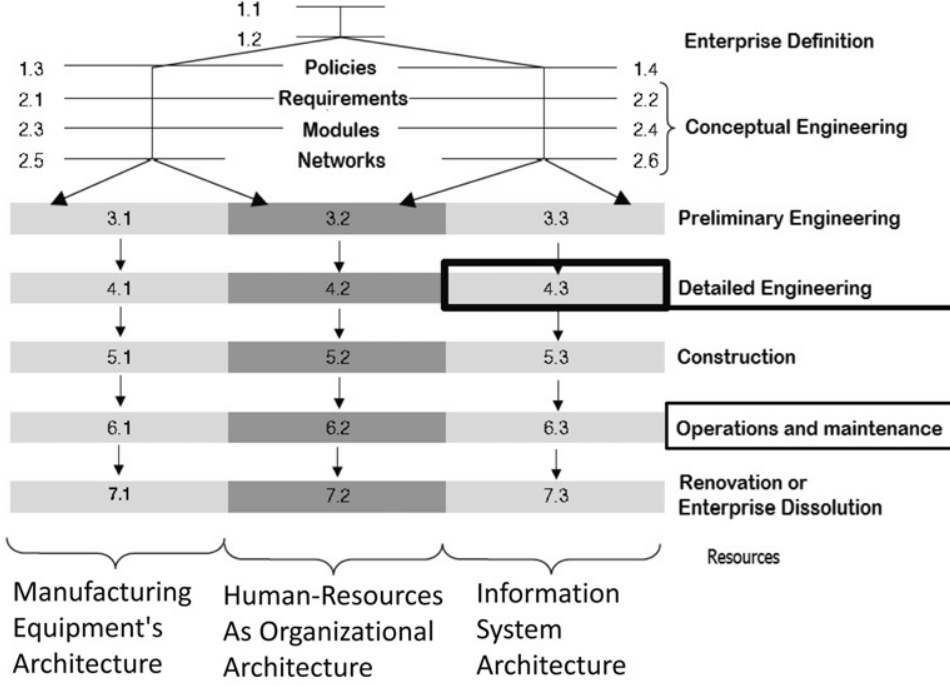

Architecture Architecture Architecture

\begin{tabular}{|c|c|l|l|l|l|l|}
\hline $\begin{array}{c}\text { Zachman } \\
\text { Table }\end{array}$ & $\begin{array}{c}\text { Data } \\
\text { (What } \\
\text { ) }\end{array}$ & $\begin{array}{c}\text { Functio } \\
n \\
\text { (How) }\end{array}$ & $\begin{array}{c}\text { Networ } \\
k \\
\text { (Where) }\end{array}$ & $\begin{array}{c}\text { Peopl } \\
\mathrm{e} \\
\text { (Who) }\end{array}$ & $\begin{array}{c}\text { Time } \\
\text { (When } \\
\text { ) }\end{array}$ & $\begin{array}{c}\text { Motivatio } \\
n \\
\text { (Why) }\end{array}$ \\
\hline $\begin{array}{c}\text { Objectives } \\
\text { / Scope }\end{array}$ & & & & & & \\
\hline $\begin{array}{c}\text { Business } \\
\text { Owner's } \\
\text { View }\end{array}$ & & & & & & \\
\hline $\begin{array}{c}\text { Architect's } \\
\text { View }\end{array}$ & & & & & \\
\hline $\begin{array}{c}\text { Builder's } \\
\text { View }\end{array}$ & & & & & \\
\hline $\begin{array}{c}\text { Scontractor's } \\
\text { View }\end{array}$ & & & & & \\
\hline $\begin{array}{c}\text { Functioning } \\
\text { System }\end{array}$ & & & & & \\
\hline
\end{tabular}

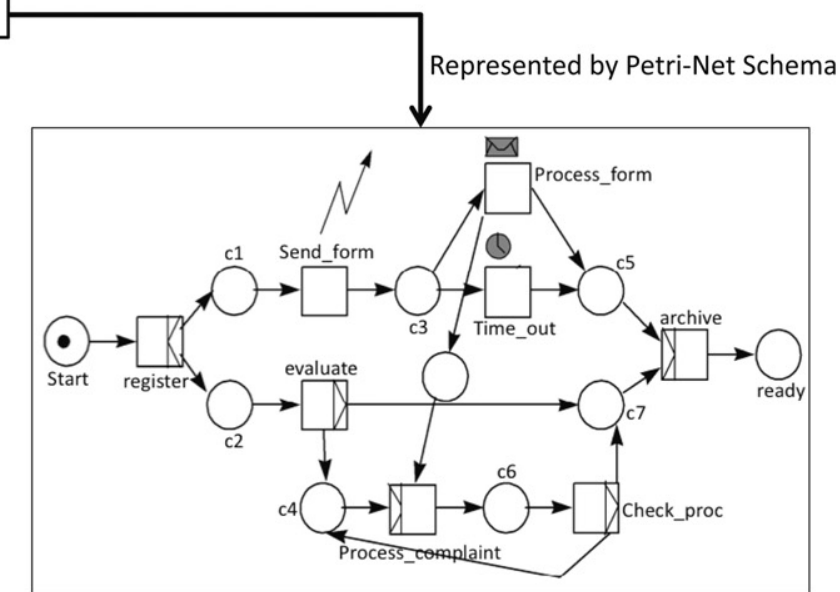

Fig. 8. New Proposed Model of Factory Templates.

main classes: firstly, describing the workflow of each life cycle stage; and secondly, characterizing the process from the point of view of the elements that interact with the process or are responsible for it.

The development of the main processes of a company or a factory can be seen as a creative job. However, if we have tools capable of supporting and analysing our creation, its performance will be improved. With this purpose in mind, we suggest that Petri-nets be seen as a valuable option to describe and simulate each group of activities that are part of each life cycle stage, as previously explained. This means that we get a very interesting tool that not only helps us to structure, formulate and communicate our ideas about the different processes but also mathematically analyses our solution, testing safety and invariance properties, reachability, boundedness, liveness, reversibility and home state, deadlock, response and waiting times, occupation rates, and other indicators that can help us to improve process performances.

As seen previously, at each stage, there are elements that need to be taken into consideration. With each of these subparts, it is important to understand which rules and limits are imposed and the perspectives of the human roles involved in the life cycle phases. Consequently, we propose the implementation of the Zachman framework as a work basis because this tool primarily aims to organise the business process, constantly attempting to understand the different points of view of the various players in the process. In each of these subparts there are questions that need answers, such as: what will be done? How will it be done? Where will it be executed and developed? Who will be responsible for it? Why is it important and why should it be done? Therefore, with this information, during the execution of each phase of the factory life, it is possible to guarantee that the entire process is going according to plan and this works as a guide for those who will implement and participate in it.

In conclusion, a framework divided into three levels was developed. The first level gives us a global view of the factory life cycle, indicating the strategy and the stages that are crucial for the successful operation of the company. At each stage of the life cycle of the factory, it is possible to model, understand and analyse each workflow using Petri-nets. At the same time, using the Zachman framework, we are capable of understanding the perspectives of the process stakeholders.

This framework could also be seen as an important support for new methods and technologies that have been emerging, such as the so-called Grid Engineering for Manufacturing [11]. This new approach, that has similar goals to the framework proposed in this paper, aims to continuously integrate the four modules that respect the life cycle of the factory. Grid Systems and technologies take on an important role, providing the infrastructures and tools to support large-scale, secure resources, data and tools sharing. 


\subsection{Dynamic modelling dimension}

After the Static domain is presented, it is now important to understand how the factory templates concept can follow and evaluate the factory behaviour.

The quality and reliability of products, services and industrial operations (Business Processes) are preconditions for high added values and the growth of demanding manufacturing sectors. Following the trends towards customised products and build-toorder strategies in manufacturing, new and efficient methods regarding preventive quality management approaches are required in all manufacturing sectors in order to assure efficiency and effectiveness. Therefore, the design of quality and reliability that should include the ability to forecast and predict the performance of complex processes and products must be focussed on. These methodologies must take into account not only the development of products by cooperative and network engineering but also the ability to design, manufacture and measure processes and the influences of a manufacturing technology choice.

According to Busi and Bititci [17], new terms are being introduced as performance management "proactive" and "passive", "feedback" and "feedforward" control, or "lagging" and "leading" measures. The development of these concepts reflects strong changes in performance management that have occurred in the last decades, transforming concepts and points-of-view on the importance of performance measurement and management, as follows:

- From performance measurement to performance management;

- From individual to collaborative performance measurement;

- From lagging to leading performance management.

Using leading measures of real-time performance, it is possible to do a feedforward control on development and deployment of plans and objectives. Otherwise, through a feedback control, the comparison of actual performance with proposed targets is based on historical lagging measures. Therefore, proactive performance management, using feedforward and feedback controls, tries to predict the future performance instead of treating processes with poor performance. In line with this, it is necessary to provide a proper combination of leading and lagging measures, thus enabling the use of forecasting methods and tools to obtain good quality predictions.

One of the main achievements of this approach is its ability to study the factory performance and to understand where improvements should be made using the "As-Is versus To-Be Performance" methodology, already described. Since the factory template concept is intended to work within the VFF European project a module called "Performance Measurement Dashboard" is being developed simultaneously, which aims to support the performance measurement, "ASIS performance". Consequently, during this topic we will concentrate our study on the "TO-BE Performance", using an estimation tool called Performance Values Estimator (PVE).

The PVE tool was designed to support the development of advanced performance management systems. The PVE's main goal is to provide estimation values and to support the definition of targets, although this tool has the potential to be used in a number of other applications. It is also a tool that allows for the fusion of all of the essential process information regarding activities, tasks, internal and external disturbances and functional requirements that can positively or negatively affect the system.

Therefore, the main purpose of this section is to explore the PVE tool, which is supported by Neural Networks (NN) and Kalman Filter [15,16] Fig. 9.

In the context of the performance estimator tool previously presented, the neural network approach will allow for the complex system modelling in a simple and intuitive manner. On the other hand, the Kalman filter will improve this approach. In fact, this component is a modelling error filter, which makes the proposed tool more immune to noises caused by internal and external disturbances. This filter is very important when we are working with complex environments, such as factories, hospitals and other complex systems where the number of input factors affect the organisational system and make its modulation more difficult. In fact, when the quantity of factors is vast and the way these variables interact with the system is complex and nonlinear, it is not feasible for it to be controlled and managed by an operator without any technical support. Subsequently, the use of the PVE tool in such situations can be very useful in order to help the decision makers stipulate the targets that will be achieved. At the same time, these estimation values contribute to manage operations, detect bottlenecks and improve processes, define strategies, evaluate and select partners or suppliers, among other management concerns.

The PVE enables a complex manufacturing system modelling, through data fusion, using an estimation tool, which focuses not only on statistical data but mainly on the factors that may influence the future. Moreover, since the success and effectiveness of performance measurement depend on the company's reaction time, it is crucial not only to reduce these reaction times, but also to anticipate them, as depicted in Fig. 11.

A mathematical model of the PVE approach will now be presented that explains the integration between a rough predictive

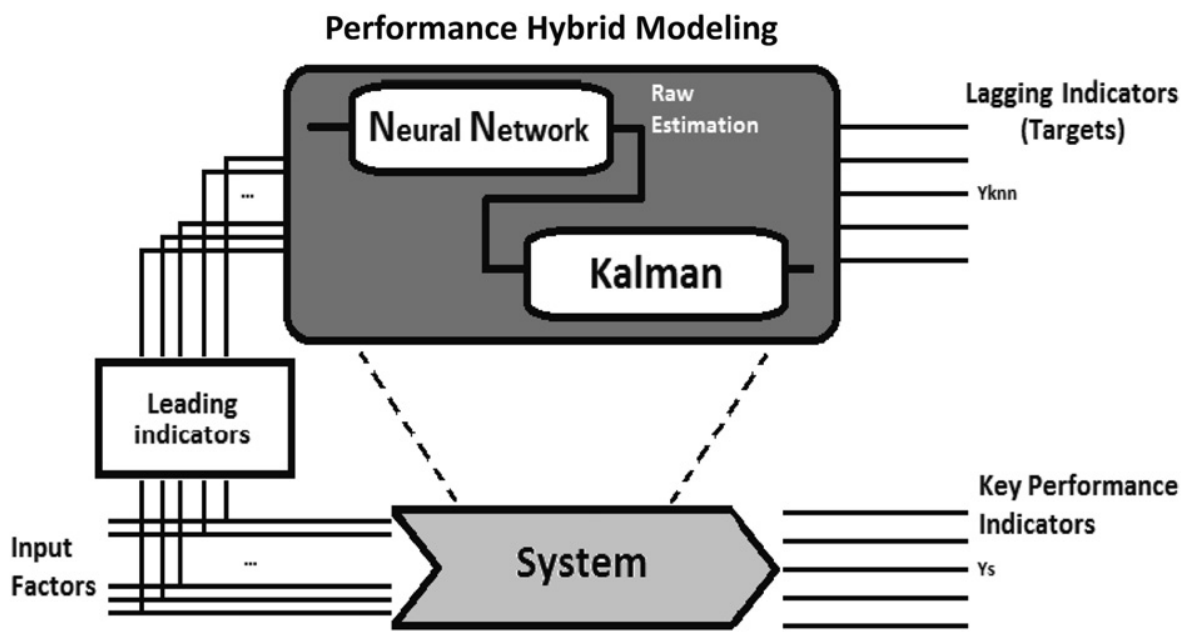

Fig. 9. Performance Value Estimator Concept. 


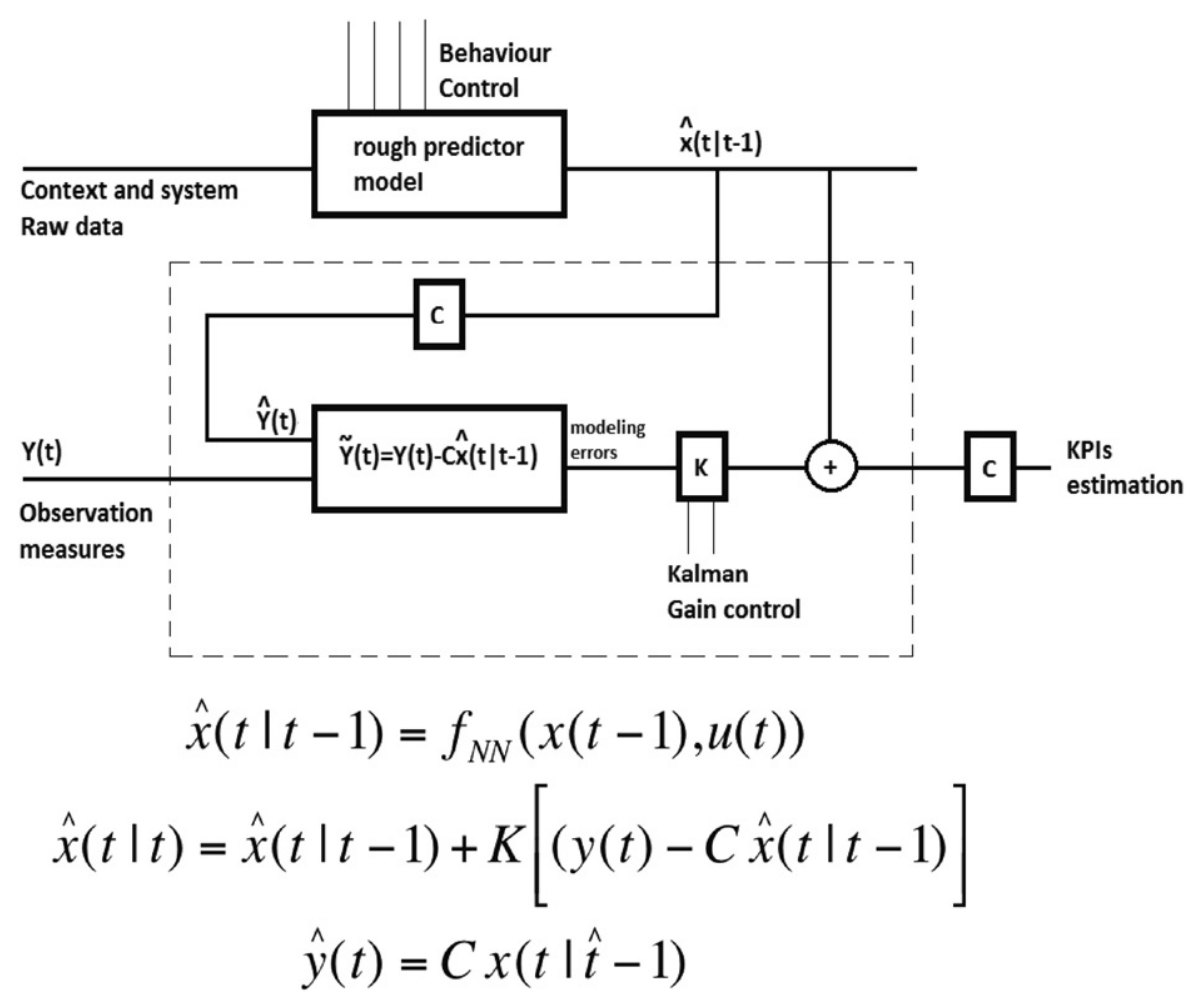

Fig. 10. Performance Estimation Concept-mathematical proof.

model (exploring a Neural Network approach) and the Kalman Filter algorithm. In a simple way, the Neural Network will receive leading and lagging factors, based on the company strategy, in order to estimate the future factory performance and taking into account the training performed before in an "offline" mode. Calculating the performance estimation, these variables should be compared with the observed measures (real system output) within the Kalman filter in an iteratively way. This stage becomes crucial since it is expected to determine the Kalman gain that minimises the estimation error. Finally, the offset specified must be added to the output of the preliminary estimation in order to eliminate possible errors. This description can be easily understood with the diagram and mathematical explanation shown in Fig. 10, as well as the results that can seen in the following section, where the PVE tool was tested and validated.

With this approach, the intention is to break with the feedback control as it is known today and through exploring an innovative process where companies can improve their processes, methodologies and technologies and, in real-time, understand and visualise what will be the impact of these changes in the long, medium and short terms. Indeed, this new paradigm aims to encourage companies to break with the normal performance management where processes and strategies are evaluated using the present performance values and to start managing their processes taking into account the future performance as a result of present actions.

In fact, this is a new concept that should be developed and studied because then it would be possible to reduce the company's reaction time to external disturbances caused by the market. It would also optimise processes in a faster and more efficient way since companies would then be able to anticipate the factory's response to the applied changes and thus be more competitive Fig. 11.

In conclusion, the PVE tool is a component that operates in parallel with the system that will be emulated, as explained in Fig. 9. This receives the measures (leading measures), in real-time, in a proactive performance management approach [17] and the predictable information about the factors that influence and positively or negatively disturb the system. With this information, the PVE is then capable of estimating targets to the chosen performance indicators for the tool. Estimates of these indicators can also be monitored in real-time and this makes it possible to estimate and predict the system's reaction to improvement processes over time.

\section{Experiments and results}

To evaluate the performance of the PVE tool that has been described and explained during the dynamic domain chapter, the model of performance estimation was evaluated through iterative testing and then applied to real use cases. Several key performance indicators (KPIs) were defined making it possible to describe the specific operational performance and the factors that influence the system's behaviour. As a test environment, a real supply chain network was chosen consisting of three manufacturing companies that operate in a collaboration context, called G3, as showed in Fig. 12. In order to successfully complete and validate this use case, this task was performed under the supervision of a G3 collaborativenetwork expert, who validated and provided some historical data.

For this use case, two different KPIs were defined in order to make the G3 performance analysis possible, in a simple and intuitive way. The key performance indicators (KPI) used in this case were defined as follows:

- DDT is the number of orders with delay on the delivery time by the total number of orders;

- NON is the number of orders with nonconformities by the total numbers of orders.

After it is applied in this use case, the PVE tool made it possible to draw some interesting conclusions on accuracy, reliability and flexibility. Different scenarios were created for each relationship between partners. The interaction here with the external 


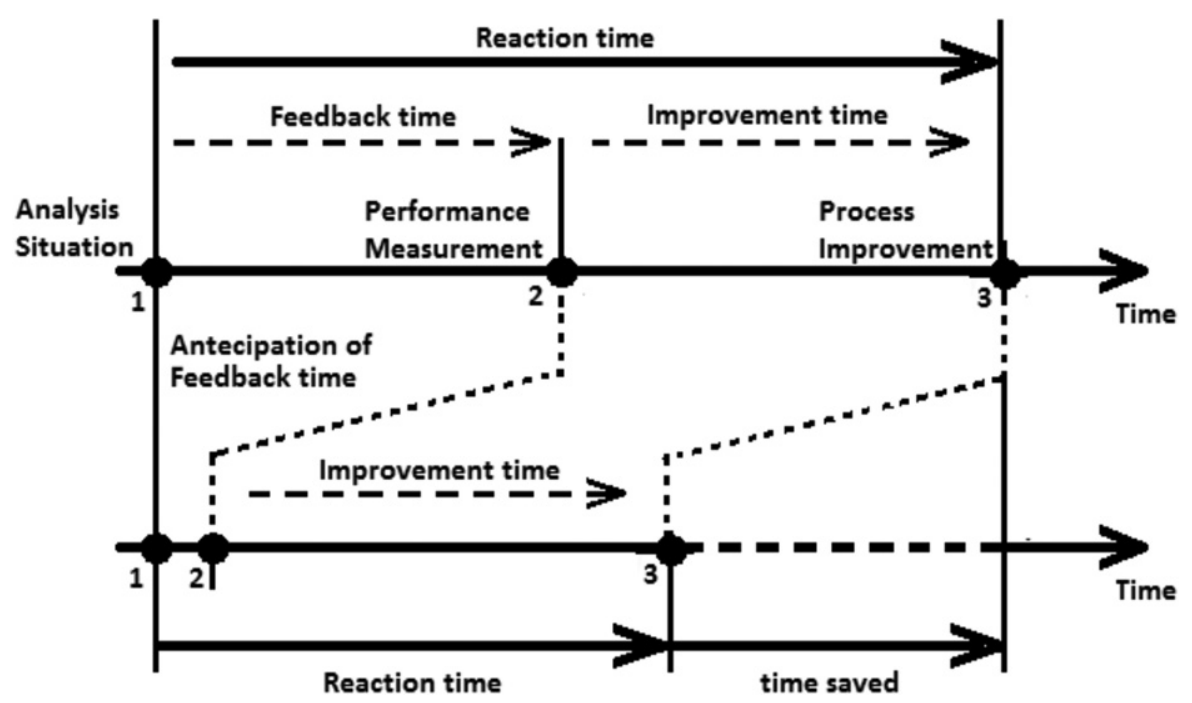

Fig. 11. Reaction time optimisation.

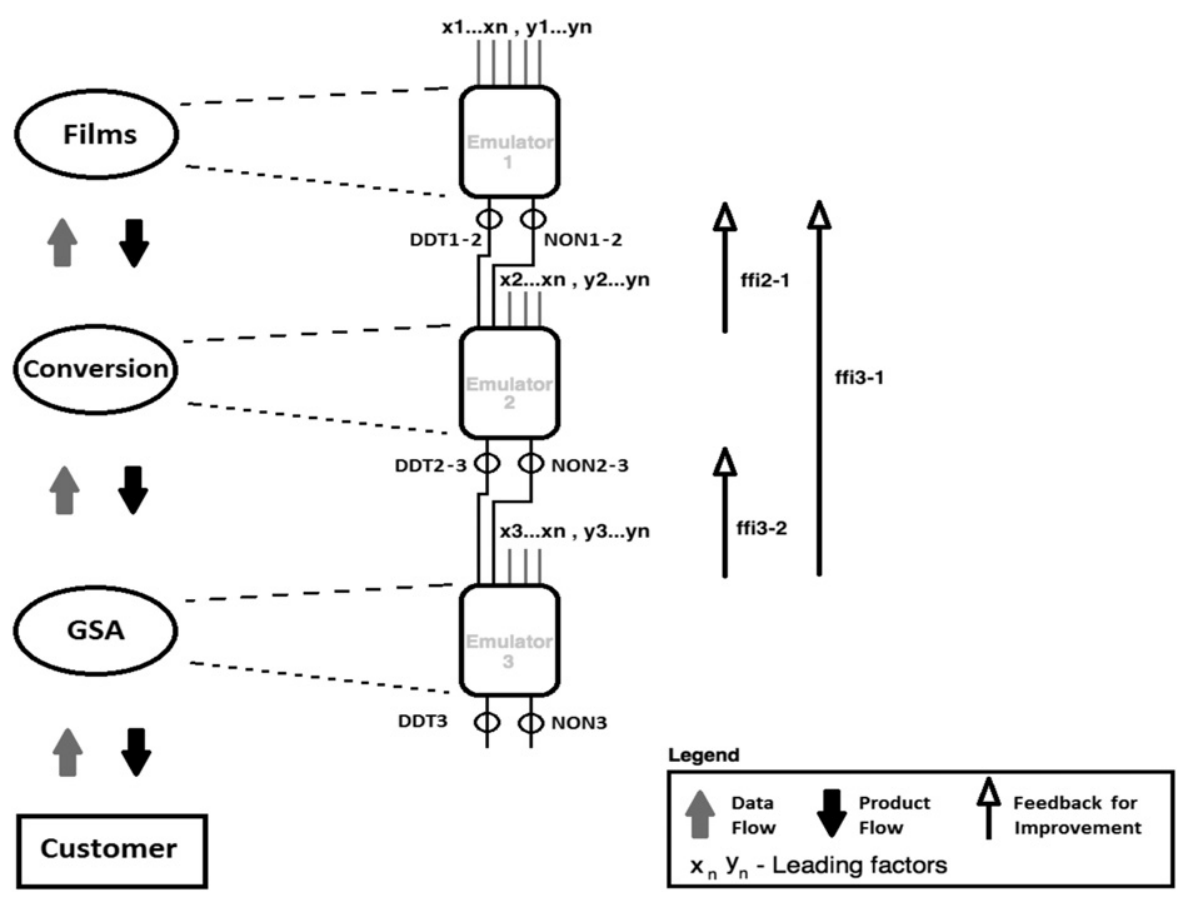

Fig. 12. Collaborative Network illustration.

environment was also included in order to improve the simulation reliability.

After the scenarios were established, the PVE tool was applied and the results were presented for each relationship, as follows. In order to facilitate understanding of the following graphs: blue corresponds to the values associated with reality; green corresponds to the values associated with neural network; red corresponds to the values associated with the PVE tool.

Therefore, the expert and GSA planner put forward two questions in order to test and validate this estimator tool.

1. The planner aims to forecast the KPI values for the next six months in order to support it in the definition of KPI targets for the medium- and long-term. The intention is to support the commitment of the production team in order to manage the factors that negatively affect the KPIs and then improve the performance, or at least keep them within these predicted values. Fig. 13 shows the results for this question.

As it is possible to observe in the figure below, after eighteen months of filter training, the PVE tool was launched to forecast the following six months. As shown in the NON graphic above, there is a smooth modelling offset error by the neural network (difference between green and blue lines). However, the Kalman Filter fulfils its function, which was to nullify this error, as proposed in the architecture of the PVE tool.

Furthermore, it was demonstrated that the PVE tool does not just follow the past trend, but also shows proactive behaviour, taking into consideration the factors that influence each month. Thus, it is possible to say that the PVE is a consistent tool because the admissible error is low and the degree of confidence is high (97\%). 

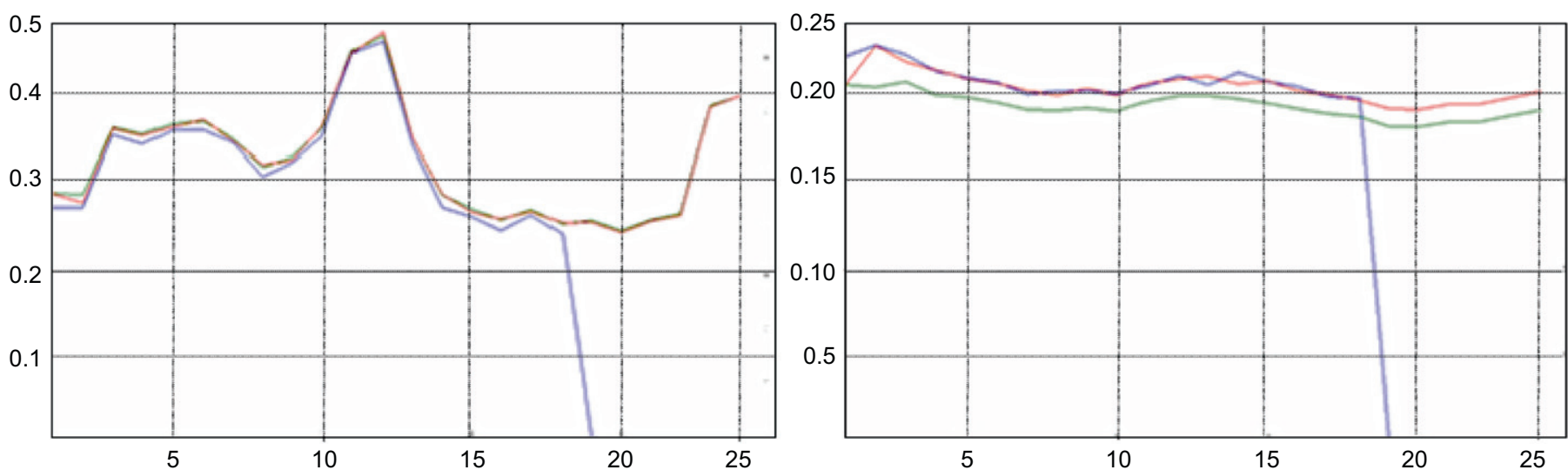

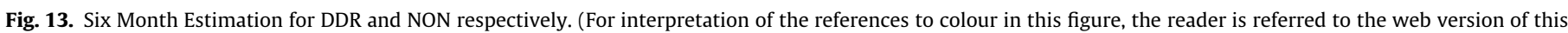
article.)
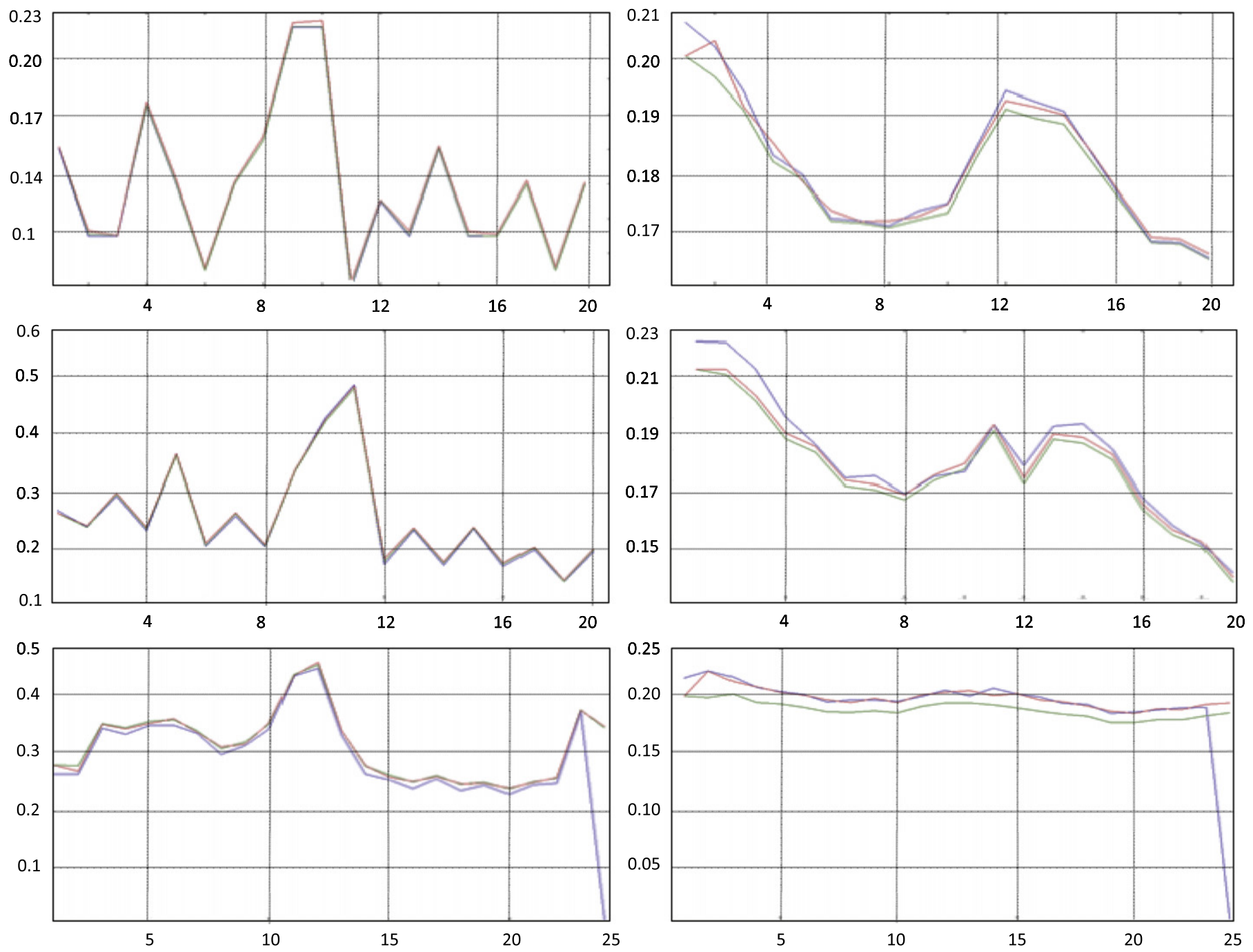

Fig. 14. (Colour online) Estimation results for DDR and NON (Relationship 1, 2 and 3).

2. The planner also aims to only forecast KPI values for the next month. It is possible that the leading factors involved cannot happen as previously expected, or changes in patterns for each factor may occur.

This strategy can guarantee that more updated values regarding changes in the leading factors are obtained when necessary and requested by the planner. The graphics of the three relationships are presented in Fig. 14. It can be seen that the interrelation between them always affects the subsequent one. In the buyer-supplier relationships in a supply chain, there are effects that consequently occur just in the following month. The result is that a mismatch in each relationship can be visualised. 
In fact, if the DDT charts of the six-month forecast and the next month's forecast are carefully analysed, it is possible to see that the forecasts in the previous month (month number 24) do not match. Indeed, the forecast performed for the following month presents more optimistic results than the six-month forecast. This happens because when the six-month forecast was performed, the estimation was carried out taking the preliminary scheduling of the preventive maintenance into account. However, when the next month estimation was performed, the planner stipulated that it was better to cancel the preventive maintenance in order to decrease the number of delays. This test was carried out in order to demonstrate that the PVE tool could be flexible enough to follow the factor changes and not just a historical data estimator. This is the reason why this tool can be very useful and powerful in a competitive and volatile market.

\section{Conclusions}

When seeking to respond to all of the needs imposed by the market and follow the tendencies and new technologies derived from the constant evolution, companies need to shorten their products life cycle, not only to fulfil costumer's requirements, but also to anticipate the actions of competitors and become market leaders. However, as a consequence, companies need to shorten their planning, operation and the life cycle of their business processes and make their manufacturing resources more adaptive to the requirements imposed by the new products, enabling the life cycle of the infrastructures to follow the life cycle of the products.

In line with these requirements, manufacturing planning efficiency and effectiveness becomes crucial in order to support increases in ramp-up performance of volatile products and in consequence decrease the time-to-market. Therefore, within these manufacturing requirements, it is essential to provide companies with tools capable of supporting decision makers as well as being capable of following, analysing and modelling the company's workflow and processes. Subsequently, it is crucial to develop a framework that makes it possible to manage the factory processes and strategy using patterns inspired by best practices as a reference and knowledge acquired through the entire lifetime of the factory.

In this context, the Factory Templates concept was explored as a new and innovative paradigm, taking into account the "Factory as a product" paradigm. These two concepts together were able not only to enable the integration of the product, factory and processes life cycle, but also to reduce the global response time, improving the re-use of knowledge and good practices, decreasing cost and time-to-market, improving ramp-up, supporting real time decision and finally, achieving an overall continuous improvement.

Within the next generation of factories, knowledge structure and management should represent the foundations of the Factory Templates in the generic factory design and planning. Therefore, this tool can be seen as an intuitive Knowledge Management system, which makes it possible not only to look for information, consistent with the context in study; but also to reuse this information. Furthermore, it supports the improvement of the activities that are considered to be the bottlenecks of the processes and finally, it stores the changes made in Knowledge Repositories Systems oriented to factory life cycle structuring, in order to make it available to all workers and company partners.

Being able to continuously understand the behaviour of the factory and project the future performance of the system in study means that the Factory Template tool makes it possible to estimate and analyse whether the factory's performance will head in the desired direction. If not, it allows managers to understand the reasons why it is not and the corrective actions that should be taken. Thus, the Factory Template module makes it possible to break with the normal feedback performance control and support the introduction of the anticipation performance control paradigm. With this change of paradigm, companies will be able to reduce their reaction time and therefore become more competitive and flexible.

In order to have this significant advantage, the Factory Templates architecture is divided into two main modelling dimensions-static and dynamic. The static dimension enables the application of the "Factory as a Product" paradigm. Here, the life cycle of the factory follows the life cycle of the product, using the simultaneous/concurrent engineering as a pillar. On the other hand, the dynamic dimension has the continuous evaluation of the life cycle of the factory as its main advantage. With this component, the Factory Templates makes it possible to follow and improve processes, detecting bottlenecks. This can be achieved using the "As-Is versus To-Be Performance" as a pillar.

The application of a successful knowledge structuring initiative, just as with the Factory Templates within an industry or service areas, can reduce agent training time, speed up new employee integration during ramp-up processes, improve communication between departments and decrease planning and design times, thus increasing its quality. Knowledge-powered problem resolution allows agents to become more confident and competent sooner than they otherwise would without a Knowledge Management practise. By having access to a knowledge base, new employees can get answers to common questions without having to constantly ask other more experienced agents.

Finally, it is important to underline the importance of the application of the Factory Template, not only within the domain of a factory but also as a collaborative network tool for the alignment of companies. In fact, more and more companies need to work together in order to become more competitive and to have the capacity to respond to market demands. Consequently, the dynamic modelling domain of the Factory Template can be very important in the selection and evaluation of partners, as well as in the anticipation of delays and malfunctions in the network.

In summary, what is proposed in this paper is a framework that gives a general overview of the company, taking into account not only the different stages of the company's life cycle, but also the perspectives of the different stakeholders and players who are responsible for the process. One important aspect is the fact that this framework should be seen as a dynamic tool, which evolves over the life cycle of the factory, learning from past mistakes or achievements and watching market demands, financial evolution and other economic and industrial aspects.

\section{Acknowledgements}

The authors would like to thank INESC Porto for their support and the VFF Collaborative Project for their inputs and contributions.

\section{References}

[1] van der Aalst WMP. Woflan: a Petri-net-based workflow analyzer. Systems Analysis Modeling Simulation 1999;35:345-57.

[2] van der Aalst WMP. Three good reasons for using a Petri-net-based workflow management system. In Proceedings of the international working conference on information and process integration in enterprises, p. 179-201, 1996.

[3] Noran O. An analysis of the Zachman framework for enterprise architecture from the GERAM perspective. Annual Reviews in Control 2003;27(2):163-83.

[4] White Jr. KPreston. Systems design engineering. Systems Engineering 1998;1: 285-302.

[5] 〈http://www.pera.net/〉 (accessed November, 2009). 
[6] VFF. Holistic, extensible, scalable and standard Virtual Factory Framework, FP7-NMP-2008-3.4-1

[7] Jovane F, Westkamper E, Williams D. The Manufuture Road: Towards Competitive and Sustainable High-Adding-Value Manufacturing. Berlin Heidelberg: Springer-Verlag; 2009.

[8] Kosanke K. CIMOSA-overview and status. Computers in Industry 1995;27:101-9.

[9] Williams TJ, Hong Li. The task force specification for GERAM and its fulfillment by PERA. Annual Reviews in Control 1997;21:137-47.

[10]〈http://www.isa-95.com/〉 (accessed November, 2009).

[11] Constantinescu C, Westkämper E. A reference model for factory engineering and design. In: Proceedings of the 6th CIRP-sponsored international conference on digital enterprise technology, vol. 66/2010, p. 1551-64, 2009.

[12] Subrata Das. High-level data fusion, ARTECH HOUSE, Norwood, 2008

[13] Hall DL, Llinas J. An introduction to multisensor data fusion. Proceedings of the IEEE 1997;85(1):6-23.

[14] Seifert M.. Collaboration Formation in Virtual Organisations by Applying Prospective Performance Measurement, Mainz, 2009.

[15] Bolland PJ, Connor JT. A constrained Neural Network Kalman Filter for price estimation in high frequency financial data. International Journal of Neural Systems 1997;8:399-415.

[16] Kim B, Primbs JA, Kalman A. Filter based model for asset prices and its application to portofolio optimization, Standford (Unpublished results, 〈http://biz.korea.ac.kr/〉 accessed November, 2010).

[17] Busi M, Bititci US. US, Collaborative performance measurement: a state of the art and future research. International Journal of Performance and Productivity Management 2006;55(1):7-25.
[18] Azevedo A, Almeida A, Bastos J, Piedade R. Virtual factory framework: an innovative approach to support the planning and optimization of the next generation factories. Management and Control of Production and Logistics 2010.

[19] Digital factories: Manufacturing design and product lifecyle management, extract from work programme, European Commission, 2011.

[20] Rohrlack T. The Digital Factory from concept to reality - a Bentley solution for automobile manufacturers. White Pater 2008.

[21] Arndt FW. The Digital Factory Planning and simulation of production in automotive industry, Informatics in Control. Automation and Robotics I 2006:27-9.

[22] Reijers AH. Design and Control of Workflow Processes. Berlin, Heidelberg, New York: Springer-Verlag; 2003.

[23] van der Aalst WMP, van Hee KM. Workflow management-models, methods and systems, academic service, Massachusetts Institute of Technology, 2002.

[24]〈http://ims.org > (accessed November, 2010).

[25] IFIP-IFAC Task Force, GERAM: Generalised Enterprise Reference Architecture and Methodology, Architectures for Enterprise Integration, March 1999.

[26] Abdalla HS. Concurrent engineering for global manufacturing. International Journal of Production Economics April 1999;60-61:251-60.

[27] Davenport Thomas H, Prusak L. Working Knowledge: How Organizations Manage What They Know. Boston, Massachusetts: Harvard Business School Press; 1998.

[28] Factories of the future PPP-FoF.ICT.2010.10-1 Smart Factories: ICT for agile and environmentally friendly manufacturing.

[29] 〈http://www.difac.net (accessed November, 2010).

[30]〈http://ist-world.net〉 (accessed November, 2010). 